\title{
Radiation graft post-polymerization of sodium styrene sulfonate onto polyethylene
}

\author{
Natalia K. Kitaeva • Vladimir R. Duflot • \\ Natalia S. Ilicheva
}

Received: 26 January 2013/Published online: 21 August 2013

(C) The Author(s) 2013. This article is published with open access at Springerlink.com

\begin{abstract}
Post-irradiation grafting of sodium styrene sulfonate (SSS) in the presence of acrylic acid (AA) has been investigated on polyethylene (PE) pre-exposed to gamma radiation at room temperature in the air. Special attention was paid to the effect of low molecular weight salt additives on the kinetics of graft copolymerization of SSS and AA. The presence of SSS links in the grafted PE copolymers was detected by the methods of UV and FTIR spectroscopy. Based on the FITR spectroscopy and element analysis data, a mechanism was proposed for graft copolymerization of SSS and AA onto PE. The mechanical properties of the graft copolymers were studied. It was established that PE copolymers grafted with sulfonic acid and carboxyl groups have higher strength characteristics (16.3 MPa) compared to the samples containing only carboxyl groups (11 MPa).
\end{abstract}

Keywords Gamma radiation .

Graft polymerization - Sodium styrene sulfonate ·

Acrylic acid · Polyethylene

$\begin{array}{ll}\text { Abbreviations } & \\ \text { AA } & \text { Acrylic acid } \\ \text { g } & \text { Grafting degree } \\ \text { HDPE } & \text { High density polyethylene } \\ \text { PAA } & \text { Polyacrylic acid } \\ \text { PE } & \text { Polyethylene } \\ \text { PE-g-PAA } & \text { Polyethylene with grafted polyacrylic } \\ & \text { acid }\end{array}$

N. K. Kitaeva $(\bowtie)$ V V. R. Duflot · N. S. Ilicheva Branch of FSUE "Scientific and Research Institute of Physical Chemistry named after L.Ya. Karpov", 109 km, Kievskoye Shosse, Obninsk 249033, Kaluga Region, Russia e-mail: kitaeva.natalia@gmail.com
PE-g-PAA-co-PSS Polyethylene with grafted copolymer of acrylic acid and styrene sulfonic acid

PSS

Sodium polystyrene sulfonate,

SSS polystyrene sulfonic acid Sodium styrene sulfonate

\section{Introduction}

Modification with ionogenic monomers is known to increase polarity and ion-exchange properties of polyethylene (PE) [1-9]. Radiation graft polymerization of various monomers is commonly used as a simple and efficient method of changing the properties of the matrix polymers. Radiation grafting can be accomplished in a "direct" manner during simultaneous irradiation of monomers and polymers [10-12], or using a post-irradiation method, which can be realized on alkyl radicals [10], peroxides and/ or hydroperoxides [13-17] produced on the polymer chains during irradiation in air. The most attractive and commercially viable process is accomplished with involvement of peroxide centers because it is possible to separate a stage of irradiation (formation of initiation centers) from actual grafting.

Post-irradiation grafting is considered promising for commercial production of strong-acid ion-exchange membranes as an alternative to labor-intensive and environmentally vulnerable multi-stage technologies available at present [7, 8, 18-22]. However, numerous efforts failed while preparing strong-acid ion-exchange membranes by post-irradiation grafting of $\mathrm{PE}$ with a sulfonic acid group containing monomer-sodium styrene sulfonate (SSS) [23]. 
Post-irradiation grafting of SSS and acrylic acid (AA) from the binary mixture of monomers onto high density polyethylene (HDPE) (is an interesting approach tried in [24-26]). The authors believed the process would occur on alkyl radicals.

The authors in [27] carried out SSS and AA grafting onto polypropylene matrix pre-irradiated with electrons in the air. The polypropylene fibers thus prepared were chemically active and contained sulfonic acid and carbonyl groups at the same time.

Thus, there exists a principle possibility for post-irradiation grafting of SSS and AA onto PE pre-irradiated at room temperature in the air.

However, in [24-27] no consideration was given to the distribution of SSS links throughout the grafted copolymer thickness, which is most significant for cation-exchange membranes in electrochemical applications. Moreover, changes in physico-mechanical properties of the film or fiber materials during modification were not investigated.

The objective of this work is to study SSS graft polymerization in the presence of AA onto PE pre-irradiated at room temperature in the air, physico-mechanical characteristics and distribution of the grafted copolymer throughout the thickness of the polymer matrix.

\section{Experimental}

\section{Irradiated polyethylene}

PE film of $13 \mu \mathrm{m}$ thickness was made in accordance with GOST $10354-82$ by extrusion of low density polyethylene. The film was irradiated in a cobalt $60\left({ }^{60} \mathrm{Co}\right)$ gamma ray source at room temperature in the air. A dose rate and absorbed dose were $2.5 \mathrm{kGy} \mathrm{h}^{-1}$ and $20 \mathrm{kGy}$, respectively.

\section{Grafting procedure}

Grafting was carried out at $70 \pm 1{ }^{\circ} \mathrm{C}$ in the aqueous solutions containing AA, SSS and ferrous ions. The concentration of $\mathrm{AA}$ in the experiments varied from 4.0 to $10.5 \mathrm{~mol} \mathrm{dm}^{-3}$; the concentrations of SSS and ferrous ions were 1 and $0.018 \mathrm{~mol} \mathrm{dm}^{-3}$ [17], respectively. Sodium chloride and sodium acetate were used as additives.

Grafting degree $(g, \%)$ was determined gravimetrically as the ratio of mass change to the initial mass of the sample

$g(\%)=\frac{\left(W_{\mathrm{g}}-W_{1}\right)}{W_{1}} \times 100$,

where $W_{1}$ and $W_{\mathrm{g}}$ are the weights of the ungrafted and grafted samples, respectively.
Measurements

The total concentration of ferrous ions and ferric ions in the solution was determined spectrophotometrically using a sulfosalicylic complex [28], the concentration of peroxide groups in the irradiated PE films was measured by the iodometric method $[29,30]$.

UV spectra were recorded in the range of wavelengths from 180 to $500 \mathrm{~nm}$ (Agilent 8453 spectrophotometer).

FTIR spectra were recorded with a Fourier spectrometer FSM 1202.

The distribution of carbon, oxygen, and sulfur throughout copolymer film thickness was investigated by scanning electron microscopy and tip scanning X-ray microanalysis using a scanning electron microscope JSMU3 "Jeol" with the energy-dispersive X-ray attachment Win EDS "Getac".

The mechanical characteristics were measured at room temperature on a universal tensile strength testing machine Zwick 0.05 at the loading rate of $10 \mathrm{~mm} \mathrm{~min}^{-1}$.

\section{Results}

Gamma irradiation of PE in the presence of oxygen and long-term storage result in the formation of peroxides (mainly dialkyl) in PE matrix. The concentration and distribution of peroxides in the volume of the polymer matrix depend primarily on radiation conditions (dose rate, absorbed dose, etc.) [16, 17]. It was established by the chemical analysis that under these radiation conditions the concentration of peroxides in PE was $0.06 \mathrm{~mol} \mathrm{~kg}^{-1}$, and they were homogeneously distributed over the film thickness. Post-irradiation grafting of vinyl monomers onto PE irradiated in the air is initiated by peroxy radicals, which are formed due to heat-induced decomposition of peroxides [31] or reduction in interaction with transition metal salts $[17,32,33]$, which is more probable in the case of PE.

In this work ferrous sulfate was used for this objective. The concentration of ferrous ions in the grafting solution was selected on the basis of previous studies and was $0.018 \mathrm{~mol} \mathrm{dm}^{-3}$ [17].

Radical post-irradiation grafting onto PE irradiated in the air can be schematically presented as a set of the following basic reactions [13, 16, 17]:

$$
\begin{gathered}
(\mathrm{PE}) \stackrel{\text { Irradiation, } \mathrm{O}_{2}}{\longrightarrow}(\mathrm{PE})-\mathrm{OO}-(\mathrm{PE}) \\
(\mathrm{PE})-\mathrm{OO}-(\mathrm{PE})+\mathrm{Fe}^{2+} \rightarrow(\mathrm{PE})-\mathrm{O}^{\bullet}+\mathrm{Fe}^{3+} \\
\quad+(\mathrm{PE})-\mathrm{O}^{-} \\
(\mathrm{PE})-\mathrm{O}^{\bullet}+\mathrm{M} \rightarrow(\mathrm{PE})-\mathrm{O}-\mathrm{M}^{\bullet} \\
(\mathrm{PE})-\mathrm{O}-\mathrm{M}^{\bullet}+\mathrm{nM} \rightarrow(\mathrm{PE})-\mathrm{O}-\mathrm{M}_{\mathrm{n}}-\mathrm{M}^{\bullet}
\end{gathered}
$$


and corresponding reactions of chain termination.

A resulting graft copolymer contains PE macromolecules with grafted chains.

The difficulty in grafting ionogenic monomers from aqueous solutions onto such hydrophobic polymer as PE is primarily due to lower rate of reaction (3) because the monomer solution does not wet the polymer surface. The second reason is low efficiency of reaction (4) caused by mutual repulsion between ionized groups of the growing polymer radical and a monomer [34].

Two approaches were used to decrease the mutual repulsion of the hydrophobic PE and ionized monomer, as well as the growing polymer radical and a monomer. The preference is given to the use of additional co-monomers with a low degree of ionization of ionogenic groups. AA is a suitable co-monomer for this objective because grafting of AA onto PE is thoroughly studied [13-17]. The use of AA could provide a hydrophilic surface of $\mathrm{PE}$ and, as a result, good wetting with strongly ionized SSS molecules. In addition, the co-monomer could decrease the repulsion of non-ionized carboxyl groups and ionized sulfonic acid groups in low-acidic grafting solutions $\left(\mathrm{pK}_{\mathrm{a}}\right.$ : $\mathrm{AA}-4.25$, organic sulfonic acids-3, polyacrylic acid (PAA)6.4-6.8, and the value of the apparent dissociation constant of polystyrene sulfonate- $0.38[35,36])$.

Thus, the use of a binary mixture of monomers (AA and SSS) makes it possible to carry out SSS grafting onto PE.

The preliminary studies on kinetics of AA grafting are shown in Fig. 1. It is seen that monomer concentration significantly affects the initial rate of grafting.

The initial rates of AA grafting (Table 1) were calculated from the kinetic data. The values show that with increasing AA concentration in the grafting solution 2.5 times the initial rate of polymerization increases nearly 55 times.

The use of a binary mixture of monomers, differing in the degree of dissociation of ionogenic groups, can change

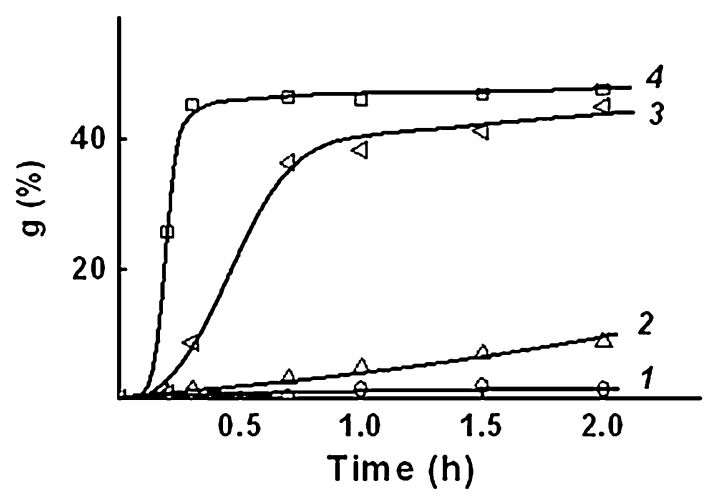

Fig. 1 Effect of monomer concentration in the grafting solution on AA grafting kinetics. AA concentration, mole $\mathrm{dm}^{-3}: 14.2,26.3,3$ $8.4,410.5$
Table 1 Effect of monomer concentration in the grafting solution on the initial rate of grafting

\begin{tabular}{lr}
\hline $\begin{array}{l}\text { Monomer } \\
\text { concentration } \\
\left(\mathrm{mol} \mathrm{dm}^{-3}\right)\end{array}$ & $\begin{array}{l}\text { Rate of } \\
\text { grafting } \\
\left(\% \mathrm{~h}^{-1}\right)\end{array}$ \\
\hline 4.2 & 2.5 \\
6.3 & 4.7 \\
8.4 & 73.2 \\
10.5 & 136.2 \\
\hline
\end{tabular}

the process of grafting. Kinetics of AA and SSS grafting from the binary mixture is shown in Fig. 2. From Fig. 2 it is seen that with increasing AA concentration in the grafting solution the initial rate of the process and grafting degree also increase. Thus, grafting degree reaches $32 \%$ for $4 \mathrm{~h}$ grafting at AA concentrations $6.3 \mathrm{~mol} \mathrm{dm}^{-3}$ and $52 \%$ for $0.5 \mathrm{~h}$ grafting at AA concentrations $10.5 \mathrm{~mol} \mathrm{dm}^{-3}$ (Fig. 2, curves 2, 3).

SSS grafting from the binary mixture of monomers is confirmed by absorption peaks in the regions of 204, 230 and $261 \mathrm{~nm}$ of the UV spectra, which correspond to benzene rings in the graft copolymer samples [37]. Similarly, in [38] the emulsion with SSS content exhibits strong absorption in the region of 200-300 nm with the peak at $254 \mathrm{~nm}$, which corresponds to vibrations of benzene ring bonds in the sodium polystyrene sulfonate (PSS) segment of the polymer chain. Thus, UV spectroscopy of the graft copolymers confirms SSS grafting onto PE in the presence of $\mathrm{AA}$ in the reaction mixture.

However, it is seen from the UV spectra that SSS grafting is still complicated in the studied conditions, despite the presence of AA in the reaction solution. This is because $\mathrm{pH}$ of the solution is 3.1-3.7 at the concentration of AA 4-4.5 mol dm ${ }^{-3}$ and 2-2.3 at 6-6.5 $\mathrm{mol} \mathrm{dm}^{-3}$, and, therefore, in addition to sulfonic acid groups, carboxyl groups are also ionized, at least, partially, which has an overall negative effect on the efficiency of SSS grafting.

To decrease the influence of electrostatic repulsion between the negatively charged growing radical and the monomer, a method of ion pair formation was used. Due to this approach the charge of carboxyl and sulfonic acid groups is screened, and the mechanism of AA and SSS grafting becomes similar to the mechanism of grafting of uncharged monomers [24, 34].

Low molecular weight sodium salts (chloride and acetate) were added into the reaction mixture to form ionic pairs, and effects of the salt additives on AA graft polymerization (Fig. 3) and graft polymerization of AA and SSS from the binary mixture (Fig. 4) were studied.

From Fig. 3 it is seen that the addition of sodium chloride, as well as sodium acetate into the grafting solution results in significant increase of the rate and maximum grafting of PAA. The maximum of PAA grafting is 1.2 times higher in the presence of sodium chloride as compared to sodium 


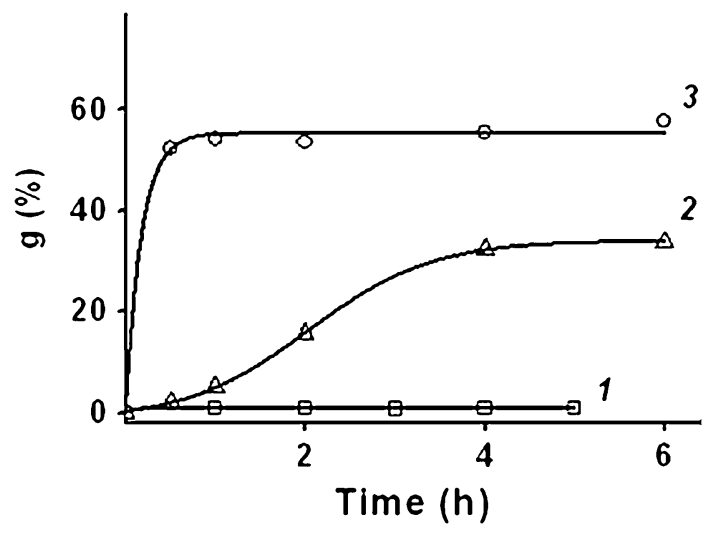

Fig. 2 Effect of AA concentration on grafting kinetics. SSS concentration: $1 \mathrm{~mol} \mathrm{dm}^{-3}$, AA concentration, mol dm${ }^{-3}: 10,26.3,310.5$

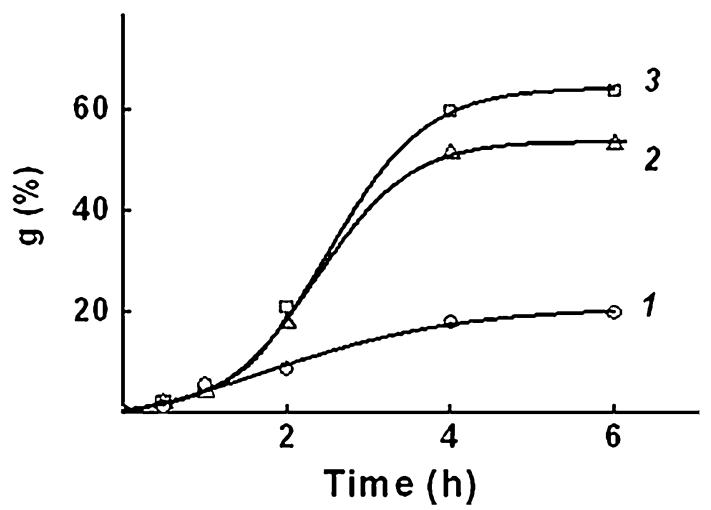

Fig. 3 Effect of sodium salt additives on AA grafting kinetics. 1 no additives, $2 \mathrm{CH}_{3} \mathrm{COONa}, 3 \mathrm{NaCl}$. Concentration, mol dm ${ }^{-3}$ : AA6.3; $\mathrm{CH}_{3} \mathrm{COONa}-2.0 ; \mathrm{NaCl}-2.0$

acetate. Dissimilar effects of different sodium salts can be explained by dissociation differences, and, consequently, by a higher content of sodium ions in case of sodium chloride at the same concentration in the solution.

The addition of sodium acetate does not affect graft polymerization of AA and SSS (Fig. 4, curves 1, 2): the initial rate grafting- $10 \% \mathrm{~h}^{-1}$, the maximum degree of grafting-34 \%. This is probably due to the fact that styrene sulfonic acid is stronger than acetic acid, and therefore, sodium acetate is a low-dissociating salt in the reaction solution containing SSS.

In case of addition of sodium chloride (Fig. 4, curve 3 ) the initial rate of grafting of AA and SSS reaches $48 \% \mathrm{~h}^{-1}$, the maximum degree of grafting-83\%, that in 2.4-2.5 times higher than without additives sodium chloride.

The effect of sodium chloride concentration on the kinetics of graft polymerization was studied on the samples of PE with grafted PAA (PE-g-PAA) (Fig. 5, curves 1,2,3), and PE with grafted copolymer of AA and SSS (PE-g-PAAco-PSS) (Fig. 5, curves 4, 5, 6).

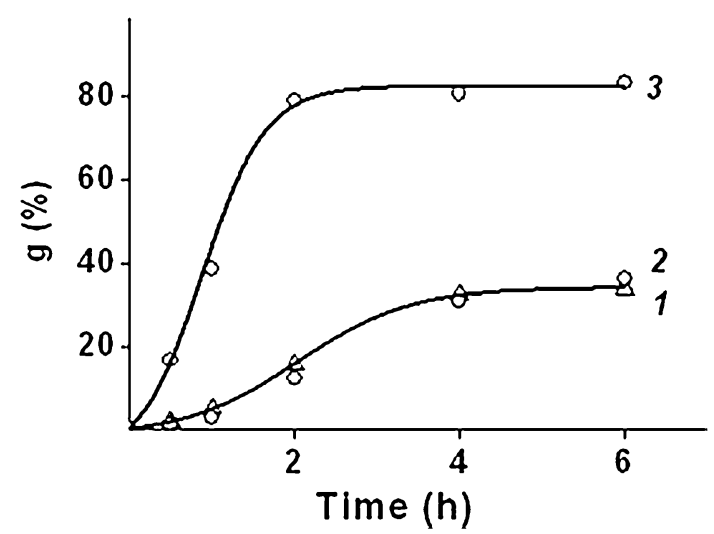

Fig. 4 Effect of sodium salt additives on the kinetics of AA and SSS grafting: 1 no additives, $2 \mathrm{CH}_{3} \mathrm{COONa}, 3 \mathrm{NaCl}$. Concentration, mol dm ${ }^{-3}$ : AA-6.3; SSS-1.0; $\mathrm{CH}_{3} \mathrm{COONa}-2.0 ; \mathrm{NaCl}-2.0$

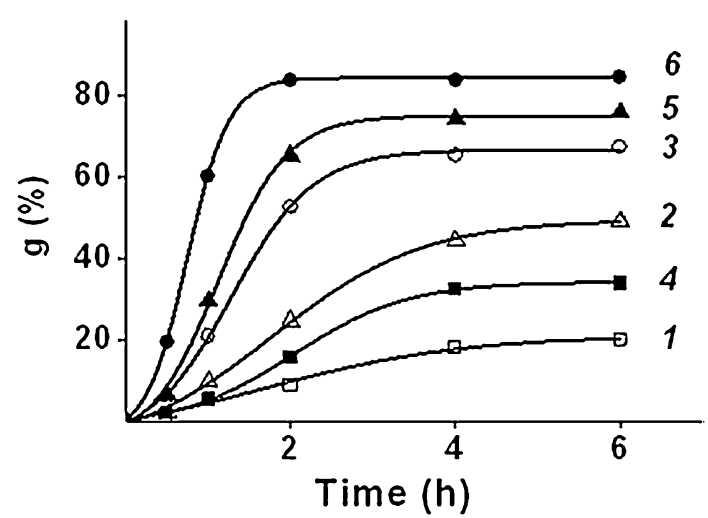

Fig. 5 Effect of sodium chloride on the kinetics of AA grafting and of AA and SSS grafting. AA concentration: $6.3 \mathrm{~mol} \mathrm{dm}^{-3}$ SSS concentration, mol dm${ }^{-3}: 1,2,30 ; 4,5,61.0 ; \mathrm{NaCl}$ concentration, $\mathrm{mol} \mathrm{dm}{ }^{-3}: 1,40 ; 2,51.0 ; 3,64.0$

It can be seen from Fig. 5 that increasing of the sodium chloride concentration in the reaction solution from 0 to $4.0 \mathrm{~mol} \mathrm{dm}{ }^{-3}$ increases both the initial rate of grafting and maximum grafting.

Herewith, the sodium chloride additive in the reaction solution affects the AA grafting more than the AA and SSS grafting, first of all because of the formation of ion pairs between sulfonic acid groups and sodium ions. The formation of the ion pairs leads to the shielding of the similar charges in the growing polymer chains with the result that the polymerization between ionized monomer and polymeric radical proceeds as if they are non-ionized.

The graft copolymers were analyzed by FTIR spectroscopy. The FTIR spectra of PSS, PE-g-PAA and PE-gPAA-co-PSS are shown in Fig. 6. It is seen that the FTIR spectra of PSS (Fig. 6, curve 4) have characteristic bands of asymmetric and symmetric vibrations at $1340-1350$ and $1150-1160 \mathrm{~cm}^{-1}$. The FTIR spectra of PE-g-PAA-co-PSS (Fig. 6, curves 2, 3) include additional peaks at 1637, 1602 
and $1496 \mathrm{~cm}^{-1}$, which correspond to the stretching vibrations of the $\mathrm{C}_{\mathrm{ar}}-\mathrm{C}_{\mathrm{ar}}$ bond [39], and the peak at $1411 \mathrm{~cm}^{-1}$, corresponding to asymmetric stretching vibrations of $\mathrm{S}=\mathrm{O}$ bond in sulfonic acid groups. The doublet at 1034 and $1010 \mathrm{~cm}^{-1}$ corresponds to the symmetric stretching vibrations of $\mathrm{S}=\mathrm{O}$ bond in sulfonic acid groups. The doublet at 835 and $776 \mathrm{~cm}^{-1}$ corresponds to deformation vibrations of $\mathrm{C}_{\mathrm{ar}}-\mathrm{H}$ bonds. The absorption bands in the spectrum of PE-g-PAA-co-PSS coincide with the absorption bands in the PSS spectrum. Similar to [25], the infrared spectra were recorded for non-irradiated PE presoaked in the solution containing the monomers (AA and SSS) and polymers (PAA and PSS). The absorption peaks corresponding to $\mathrm{C}=\mathrm{O}$ and $\mathrm{S}=\mathrm{O}$ bond vibrations were not recorded in the spectra of non-irradiated PE. Thus, the method of FTIR spectroscopy also confirms SSS grafting onto PE.

To assess the content of the grafted macromolecules in the copolymer, the FTIR spectra were pre-recorded for the reference samples of PAA and PSS homopolymers of preset composition. Then the characteristic absorption bands were selected at the frequency of $1040 \mathrm{~cm}^{-1}$ and $1722 \mathrm{~cm}^{-1}$, which correspond to the stretching symmetric vibrations of $\mathrm{S}=\mathrm{O}$ bond in the sulfonic acid group and to the stretching vibrations of $\mathrm{C}=\mathrm{O}$ bond in the carboxyl group, respectively [39-41]. Then the mixtures of known different containing of PAA and PSS were prepared gravimetrically and FTIR spectra were recorded. In addition, a calibration curve was obtained for the ratio $D_{1722} /$ $\mathrm{D}_{1040}$ optical densities to the ratio of PAA and PSS molar concentrations.

Based on the analysis of the graft copolymer composition at different times of grafting, it is also possible to make an assumption about the mechanism of AA and SSS grafting onto PE. Thus, Fig. 7 shows the FTIR spectra processed for the kinetics of AA and SSS grafting in the presence of $1.0 \mathrm{~mol} \mathrm{dm}^{-3}$ sodium chloride (Fig. 5, curve 5). It can be seen in Fig. 7 that SSS grafting is delaying as

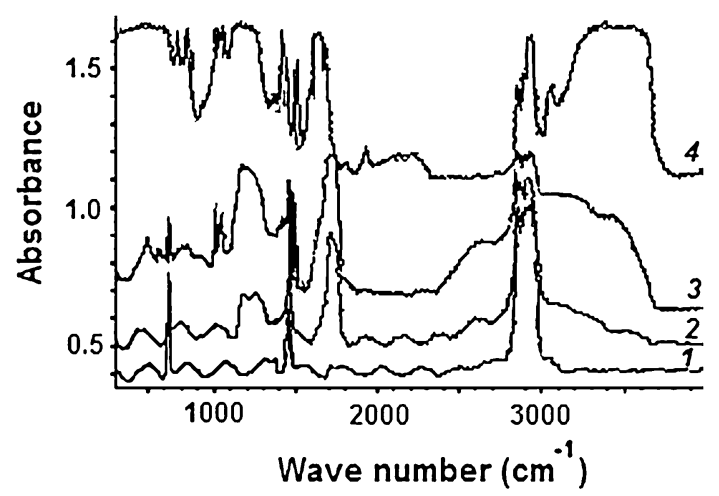

Fig. 6 FTIR spectra: 1 PE-g-PAA $(g=14.8 \%)$; 2 PE-g-PAA-coPSS $(g=11.8 \%) ; 3$ PE-g-PAA-co-PSS $(g=82.1 \%)$; 4 PSS compared to AA grafting. The grafting of AA and SSS is almost complete in $2 \mathrm{~h}$, but the proportion of grafted SSS is $\sim 23 \mathrm{wt} \%$ of the total graft copolymer amount.

A deceleration character of SSS grafting onto PE from the binary mixture of monomers is also confirmed by comparison of element distribution (carbon, oxygen, sulphur) throughout the copolymer thickness after $0.5 \mathrm{~h}$ and $4 \mathrm{~h}$ of AA and SSS grafting (Fig. 8).

It can be seen from Fig. 8a that after $0.5 \mathrm{~h}$ AA and SSS grafting onto $\mathrm{PE}$, oxygen is concentrated mainly on the sample surface, and sulfur content in the grafted copolymer is negligible. In $4 \mathrm{~h} \mathrm{AA}$ and SSS grafting, sulphur appears in the sample composition in addition to oxygen, which indicates the presence of the grafted PSS in the copolymer (Fig. 8b).

Thus, it can be concluded that only AA is grafted from the binary mixture of monomers at the initial stage of the process, and grafted PAA is mainly localized on the surface of PE. Further grafting results in increasing PAA content and appearance of the grafted PSS in the copolymer, which correlates well with the FTIR spectroscopy data.

Dependence 2 and 3 (Fig. 8b) shows that the content of oxygen and sulphur is uniformly on the surface and inside the film after $4 \mathrm{~h}$ of grafting. Thus both PAA and PSS are homogeneously distributed throughout the thickness of the grafted copolymer with increasing grafting time.

According to [19, 24, 26, 27], the presence of sulfonic acid groups positively affects water absorption ability of the graft copolymer. As a consequence, the degree of swelling changes and cation exchange properties increase. On the other hand, the same groups can decrease such properties of graft copolymers as mechanical strength,

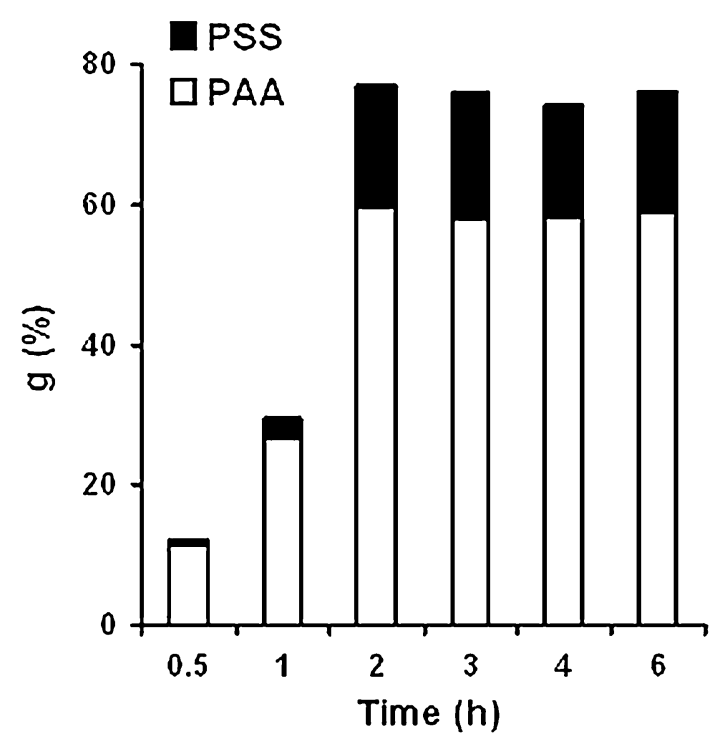

Fig. 7 Effect of grafting time on content of the grafted polymer. $\mathrm{NaCl}$ concentration: $1.0 \mathrm{~mol} \mathrm{dm}{ }^{-3}$, concentration, mol dm ${ }^{-3}$ : AA6.3; SSS-1 


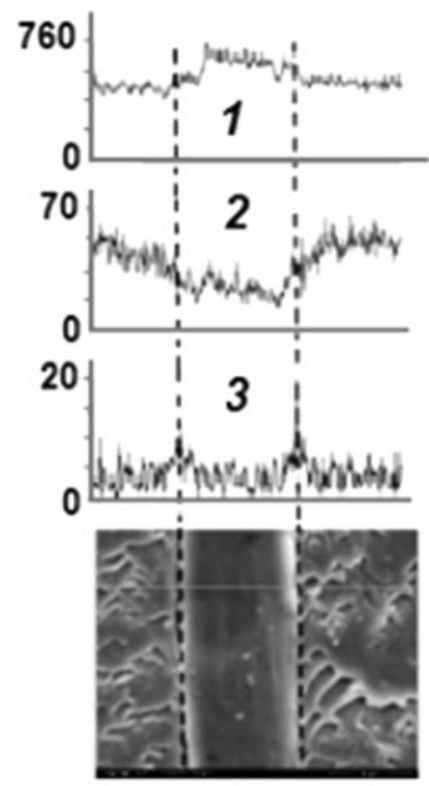

(a)

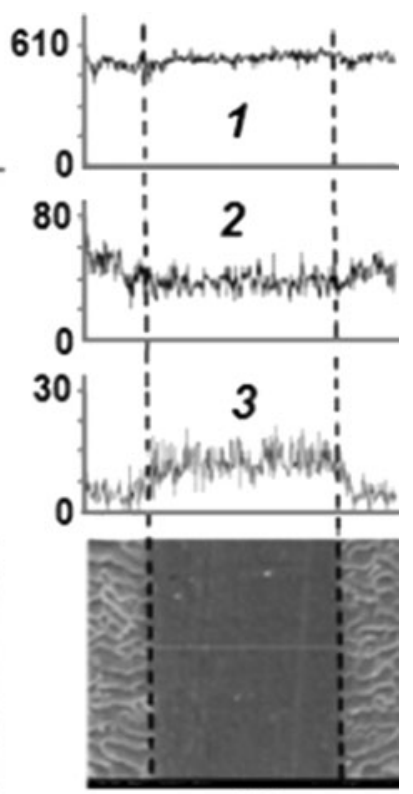

(b)
Fig. 8 Effect of grafting time on distribution of carbon (1), oxygen (2) and sulphur (3) throughout the thickness of the grafted copolymer. Time of grafting, h: a $0.5 ; \mathbf{b} 4$

which is important for practical applications. Moreover, the mechanical properties depend equally on the total content and distribution of sulfonic acid groups on the surface and in the bulk of the graft copolymer. However, the data on distribution and effect of sulfonic acid groups on the mechanical properties during AA and SSS grafting from the binary mixture can be hardly found in scientific publications.

Investigations of the mechanical properties showed that copolymer strength did not change with the time of AA grafting onto PE in the absence of SSS. However, with SSS incorporation to the monomer mixture a sharp increase of the graft copolymer strength was observed in $2 \mathrm{~h}$. The value of tensile strength increased from 10.2 MPa for the initial PE to 16.3 MPa for the copolymer with grafted PAA and PSS.

Elasticity studies of the graft copolymers showed an extreme dependence on the time of polymerization. After $2 \mathrm{~h}$ of grafting elastic properties drastically decrease, and in $4 \mathrm{~h}$ the elasticity is $64.0 \%$ for copolymers with grafted PAA and $21.5 \%$ for the copolymer with grafted PAA and PSS.

This effect of ionogenic monomers on the mechanical properties of grafted copolymers PE-g-PAA-co-PSS is attributed foremost to their frontal character of PE grafting. Starting from the surface of PE film, fronts of grafting penetrate deep into PE sample so grafted copolymer has a higher flexibility in almost constant strength characteristics. After $2 \mathrm{~h}$ of grafting fronts getting close, grafting is ended and more homogeneous system, consisting of PE and uniformly distributed through its thickness grafted macromolecules, is appear. It can be proved by the presented above data obtained from the FTIR spectra (Fig. 7) and by elemental analysis (Fig. 8).

After $2 \mathrm{~h}$ of grafting the effect of grafted PAA or grafted PAA-PSS on the mechanical properties becomes the dominant. This is increases the strength of the graft copolymer and reducing their elasticity, because unlike PE, PAA and PSS are glassy polymers [42-44].

Thus, $2 \mathrm{~h}$ of grafting is the critical point wherein specify system properties (mechanical, electrical, swelling etc.) are changed dramatically.

Physical and chemical properties of PE copolymers with grafted PAA and PSS were comparable with the values of PSS swelling in aqueous solution, cation exchange capacity and ionic conductivity given in [24-27].

\section{Conclusions}

Thus, the studies of post-irradiation graft polymerization of SSS onto PE in the presence of AA experimentally proved a possibility of grafting highly ionized SSS monomer onto PE pre-exposed to gamma-irradiation at room temperature in the air.

It was established that graft polymerization of SSS and AA from the binary mixture onto PE has a delaying nature.

In addition to confirm the presence of SSS links in the graft copolymer the methods of UV and FTIR spectroscopy and element analysis were used. They also demonstrated that SSS is grafted not only on the surface of PE, but also inside the polymer matrix.

Open Access This article is distributed under the terms of the Creative Commons Attribution License which permits any use, distribution, and reproduction in any medium, provided the original author(s) and the source are credited.

\section{References}

1. Pikaev AK (1987) Modern radiation chemistry. Solids and polymers. Applied aspects. Nauka, Moscow

2. Kabanov VYa (1989) Radiation induced graft polymerization in the U.S.S.R. High Energ Chem 33(1):51-60

3. Kabanov VYa, Kudryavtsev VN (2003) Modification of polymers by radiation graft polymerization (State of the Art and Trends). High Energ Chem 37(1):1-5

4. Kabanov VYa, Feldmann VI, Ershov BG, Polikarpov AI, Kiryukhin DP, Apel PYu (2009) Radiation chemistry of polymers. High Energ Chem 43(1):1-18

5. Timakova KA, Tarasov AV, Fedotov YuA, Lepeshin SA, Panov YuT (2012) Modification of polymeric films, coatings and membranes. Membr Membr Technol 2(2):74-84

6. Krul' LP, Polikarpov AP (1990) Progress in the synthesis of grafted materials using radiation graft polymerization. Russ Chem Rev 59(5):469-481 
7. Gupta B, Anjum N, Revagade N, Jain R, Singh H (2004) Development of membranes by radiation-induced graft polymerization of monomers onto polyethylene films. J Macromol Sci 44(3):275-309

8. Nasef MM, Hegazy E-SA (2004) Preparation and applications of ion exchange membranes by radiation-induced graft copolymerization of polar monomers onto non-polar films. Prog Polym Sci 29(6):499-561

9. Rosenblum ND, Kocherginskaya LL, Gitkova LG, Smirnova IV, Larchenko GYu, Marteks EV, Margolin DM, Terekhov VD, Vasilev LV (1975) Radiation-chemical synthesis of carboxylcontaining homogeneous ion-exchange membranes. Int Polym Sci Technol 9:20-22

10. Ivanov VS (1988) Radiation chemistry of polymers. Khimiya, Leningrad

11. Tsetlin BL, Vlasov AV, Babkin IYu (1973) In: Kargin VA (ed) Radiation chemistry of polymers. Nauka, Moscow

12. Vlasov AV, Golubev VN, Tsetlin BL, Bokun VCh, Ponomarev AN (2002) In: Simonyan VO (ed) Promising high-efficient technologies and materials for textile industry. FGUP TsNIKhBI, Moscow

13. Ishigaki I, Sugo T, Senoo K, Takayma T, Machi S, Okamoto J, Okada T (1981) Synthesis of ion exchange membrane by radiation grafting of acrylic acid onto polyethylene. High Energ Chem 18(5):899-905

14. Dmitrenko AV, Mech AM, Agapitov AP (1990) Features of graft co- and homopolymerization of acrylic and methacrylic acids initiated from the bulk of solid polymer matrix. Polym Sci Ser A 32(3):523-528

15. Grigoriev YuN, Savostyanov VS, Kritskaya DA, Ponomarev AN, Zagorets PA (1982) Radiation graft polymerization of acrylic acid onto high density polyethylene powder. Polym Sci Ser A 24(8):1765-1768

16. Zamyslov RA, Kitaeva NK, Dobrov IV (1992) Kinetics of grafting of acrylic acid to radiation-peroxidized polyethylene. Polym Sci Ser A 34(6):11-17

17. Kitaeva NK (2001) Synthesis and control of properties of polyethylene membranes with grafted polyacrylic acid. Dis for the degree of Candidate of Science (Chemistry), Moscow

18. Flint SD, Slade RCT (1997) Investigation of radiation-grafted PVDF-g-polystyrene-sulfonic-acid ion exchange membranes for use in hydrogen oxygen fuel cells. Solid State Ionics 97(1-4):299-307

19. Nasef M, Saidi H, Dahlan KM (2010) Radiation grafted poly(vinylidene fluoride)-graft-polystyrene sulfonic acid membranes for fuel cells: structure-property relationships. Chin J Polym Sci 28(5):761-770

20. Gupta B, Muzyyan N, Saxena S, Grover N, Alam S (2008) Preparation of ion exchange membranes by radiation grafting of acrylic acid on FEP films. Radiat Phys Chem 77(1):42-48

21. Yamaki T, Asano M, Maekawa Y, Morita Y, Suwa T, Chen J, Tsubokawa N, Kobayashi K, Kubota H, Yoshida M (2003) Radiation grafting of styrene into crosslinked PTEE films and subsequent sulfonation for fuel cell application. Radiat Phys Chem 67(3-4):403-407

22. Pirogov AV, Chernova MB, Nemtseva DS, Shpigun OA (2002) Effect of sulfonating reagent on the method of synthesis and ionochromatic properties of sulfonated styrene-divinylbenzene sorbents with high crosslinking degree. News of Moscow University Ser 2 Chem 172(3):172-177

23. Tsuneda S, Saito K, Mitsuhara H, Sugo T (1995) Novel ionexchange membranes for electrodialysis prepared by radiation- induced graft polymerization. $\mathrm{J}$ Electrochem Soc 142(11):3659-3663

24. Jianhua Z, Zhiqiang H, Wang W, Jianqiu Zhang ES, Pino JG, Tong L (2007) The effect of additives on radiation-induced grafting of AA and SSS onto HDPE. J Radioanal Nucl Chem 273(2):479-484

25. Jianhua Z, Zhang J, Sun G, Zhou R, Liu Z (2009) Preparation of cation-exchange membrane containing bi-functional groups by radiation induced grafting of acrylic acid and sodium styrene sulfonate onto HDPE: influence of the synthesis conditions. J Radioanal Nucl Chem 279(1):185-192

26. Reddy PRS, Agathian G, Kumar A (2005) Preparation of strong acid cation-exchange membrane using radiation-induced graft polymerization. Radiat Phys Chem 73:169-174

27. Bondar YuV, Li SV (2007) Synthesis of chemically active polymeric fibers bearing sulfo and carboxy groups. Russ J Appl Chem 80(11):1894-1898

28. Lurie YuYu, Rybnikova AI (1974) Chemical analysis of industrial waste water. Khimiya, Moscow

29. Zamyslov RA, Kitaeva NK, Karpo BS (1995) Effect of inhibitor on grafting copolymerization of acrylic acid to polyethylene. Polym Sci Ser A 37(1):39-43

30. Savostyanov VS, Kritskaya DA, Ponomarev AN (1986) Study of peroxide formation in gamma-irradiated polyethylene by the method of iodometric titration. High Energ Chem 20(2):153-158

31. Berlent U, Hofman A (1963) Grafted and block-copolymers. Publishing House "Foreign Literature", Moscow

32. Savostyanov VS, Pomogailo AD, Kritskaya DA, Ponomarev AN (1989) Radiation-induced graft polymerization of metal-containing monomers. Polym Sci Ser A 27(6):1935-1956

33. Dmitrienko AV, Mech AM, Zamyslov RA (1990) Salts of variable valence metals in the process of initiating graft polymerization from solid peroxidized matrix. Polym Sci Ser A 32(3):542-547

34. Kabanov VA, Topchiev DA (1975) Polymerization of ionizable monomers. Nauka, Moscow

35. Chemical Encyclopedia (1988) In: Knunyats IL, Zefirova NS (eds) Soviet encyclopedia, Moscow

36. Encyclopedia of Polymers (1974) In: Kargin VA (ed) Soviet encyclopedia, Moscow

37. Vasiliev VP (2003) In: Physico-chemical methods of analysis. Drofa, Moscow

38. Wan T, Zang TS, Wang YC, Zhang R, Sun XC (2010) Preparation of water soluble Am-AA-SSS copolymers by inverse microemulsion polymerization. Polym Bull 65:565-576

39. Tarutina LI, Pozdnyakova FO (1986) Spectral analysis of polymers. Chemistry, Leningrad

40. Gilbert EE (1969) Sulfonation of organic compounds. Chemistry, Moscow

41. General organic chemistry (1983) In: Barton D, Ollis UD (eds) Chemistry, Moscow

42. Osipenko IF, Polikarpov AP, Prokopchuk NR, Krul LP (1983) Stress-strain properties of graft copolymers of polyethylene and acrylic acid. Polym Sci Ser C 21(7):527-530

43. Mukherjee AK, Gupta BD (1985) Radiation-induced graft copolymerization of methacrylic acid onto polypropylene fibers. I. Effect of synthesis conditions. J Appl Polym Sci 30(6):2643-2653

44. Sergeeva LM, Fainleib AM, Tolstov AL, Bardash LV (2006) Influence of irradiation on properties of polyolefins and their blends with the other polymers. Polym J 28(4):271-283 